\title{
Reprints. Reprints. Reprints.
}

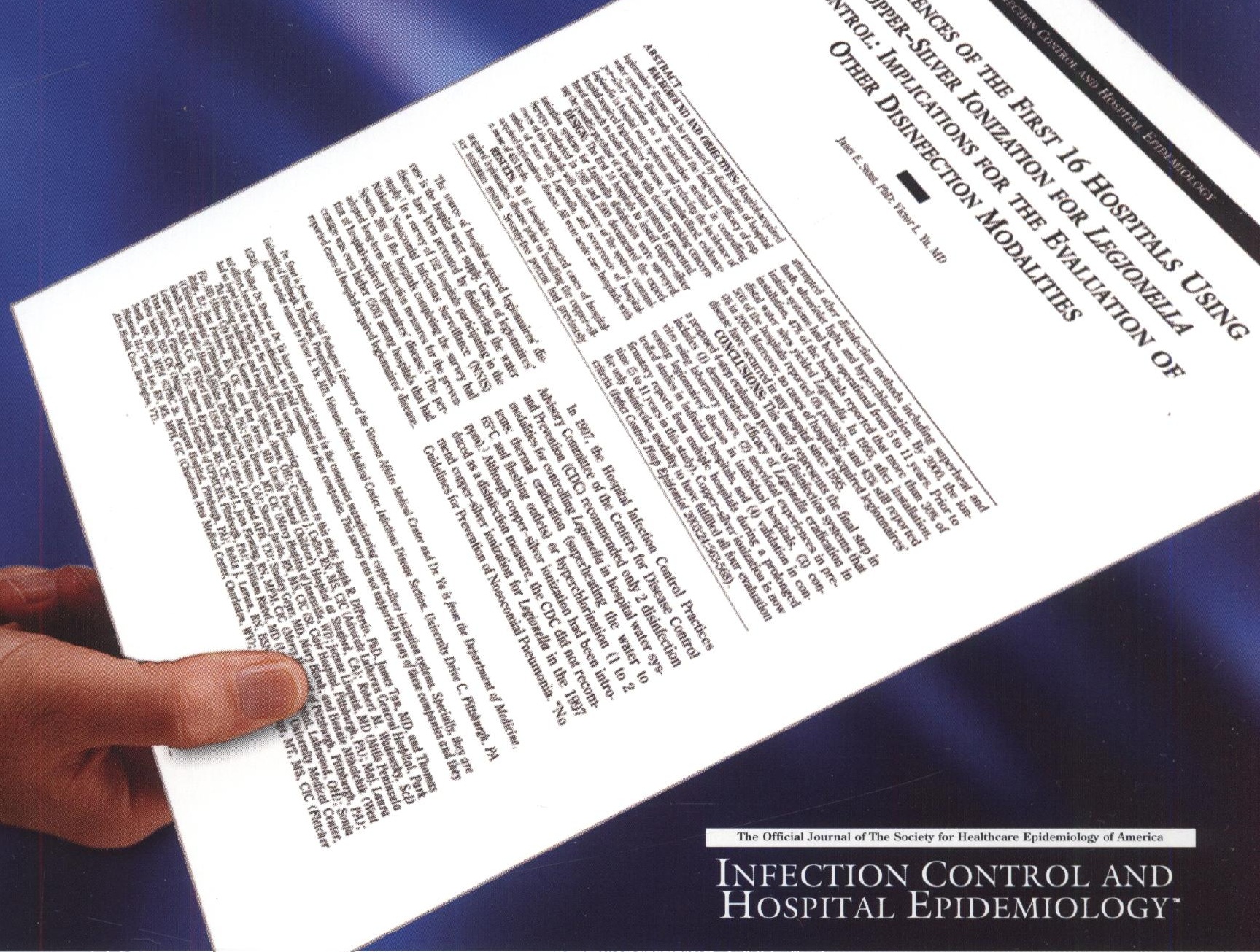

\section{Your story is worth repeating.}

Article reprints offer an easy solution to help you distribute information to your patients and colleagues. When you find an article in INFECTION CONTROL AND HOSPITAL EPIDEMIOLOGY, don't bury it in the archives - spread the word with an INFECTION CONTROL AND HOSPITAL EPIDEMIOLOGY reprint.

\section{Call today for a FREE quote and learn how INFECTION CONTROL AND HOSPITAL EPIDEMIOLOGY can help you.}

\section{Our professional customized article reprints offer*:}

- Quick turn-around time

- Full color or black-and-white reproduction

- 8.5" x 11 " booklet bound format

- High-quality glossy stock

For a FREE quote, call John Kain, Director of Reprint Sales, at 1-800-257-8290, ext. 238 (856-848-1000 in N.J. or outside the U.S.); e-mail: jkain@slackinc.com; or visit us online at slackinc.com/reprints. 
